\title{
Nicolás Lynch. Para una crítica de la democracia en América Latina, Buenos Aires, CLACSO, 2020, 143 págs.
}

En este nuevo libro, Nicolás Lynch analiza los debates en torno al significado de la democracia en América Latina, a partir de la teoría y la práctica de la historia reciente escrita las últimas décadas. La propuesta del autor se torna especialmente relevante, teniendo en cuenta el desarrollo -y cierto retroceso- de los gobiernos populares de izquierda a comienzos del siglo XXI en la región. La novedad interpretativa propuesta, radica en entender a la democracia actual no como una disputa entre dictadura populista y democracia liberal -visión difundida por el neoliberalismo y algunas derechas de la región- sino más bien a partir de dos formas de concebir la democracia: una de masas y de corte social, otra elitista y de carácter procedimental.

El autor entiende que la democracia latinoamericana debe comprenderse como parte de la lucha autóctona de los pueblos, más que un producto importado de occidente o Norteamérica. En suma, este estudio de historia reciente adquiere gran relevancia ante los actuales problemas de diversos países que presentan convulsiones, desde amplias protestas sociales hasta desplazamientos de sus jefes de Estado como Venezuela, Chile, Brasil, Ecuador y Bolivia.

Así, en un primer capítulo, retoma el argumento analítico que propone "mirar desde el sur", a partir de un conjunto de factores históricos como las raíces culturales propias, la oposición al coloniaje y la vivencia común de las luchas populares. Esto, argumenta Lynch, le da ciertas connotaciones específicas al significante de la democracia en la región, como por ejemplo el doble carácter de democracia social y democracia política. En definitiva, la propuesta se inclina por recuperar las raíces históricas y las estructuras sociales propias evitando los divorcios analíticos de las tradicionales teorías de Guillermo O’Donnell y Philippe Smitter y los más recientes análisis politológicos de Scott Mainwaring y Aníbal Pérez-Liñan.

El segundo capítulo parte de una crítica y una reivindicación: los análisis actuales de la democracia han olvidado la condición dependiente (persistente a su vez en condiciones históricas concretas) y, dado la persistencia de la hegemonía neoliberal en la región, se torna una necesidad retomar aquella discusión. La dependencia, vista desde el argumento del libro, es un producto histórico que en nuestros días es tramitada y procesada de formas particulares, que afectan a una democracia que existe con cierta dependencia de los centros de poder mundial.

El autor critica la teoría de la modernización inscripta en la segunda mitad del siglo XX y retoma las teorías de la dependencia formuladas por diversos cientistas sociales, como Raúl Présbich, Ricardo Cardozo, Enzo Faletto, Ruy Mauro Marini, así como de la posterior crítica de José Nun y Aníbal Quijano al dualismo cepalino, señalando las conexiones entre los sectores capitalistas en países dependientes. En suma, el recorrido que presenta Lynch en este apartado permite replantearnos una mirada latinoamericana lejana al neoliberalismo 
que proponga abordar de forma más independiente nuevos problemas socioeconómicos como la explotación del trabajo, la precariedad, la diversificación productiva y otras problemáticas que provocan profundas desigualdades.

En el tercer capítulo se aborda la importación del concepto de democracia desde comienzos del siglo XIX en la tradición española, la posterior importación de las elites oligárquicas de fines de siglo y, finalmente, el largo proceso de desventuras democráticas durante la mayor parte del siglo XX. Entre fines del siglo XX y principios del siglo XXI, Lynch identifica lo que entiende como paradigma hegemónico de democracia liberal, ampliamente difundido desde Norteamérica con más preferencia por lo liberal que por lo democrático. Luego de examinar los fracasos de este "giro a la derecha democrático" de fines del siglo $\mathrm{XX}$, el autor desagrega el análisis de lo que decide denominar "gobiernos de signo nacional-popular" a partir de los proyectos políticos democratizadores, sus bases sociales, el papel de la hegemonía y los liderazgos construidos.

En el cuarto capítulo Lynch se ocupa de lo que denomina la "grieta de las dictaduras" de los años 1960, 1970 y 1980 que, aunque no se dieron en todos los países, marcaron a las democracias posteriores significativamente, sino es que aún siguen haciéndolo. No obstante, el autor las diferencia entre: dictaduras tradicionales, regímenes burocráticos autoritarios y reformistas liberales, que variaron en intensidad en torno a objetivos represivos y el reformismo social propuesto, así como de su involucramiento con el Norte, especialmente significativo en los últimos casos. En resumen, el autor describe con minuciosidad las dictaduras personalistas de la primera ola, las de perfil militar y tecnócratas de la segunda tanda y las destinadas ya a un reformismo de corte liberal en la última etapa.

En la misma línea el quinto capítulo avanza en un examen de las transiciones a la democracia develando que estas pueden ser progresivas o regresivas de acuerdo con su contexto y con los actores involucrados en dichos procesos. Así, el autor analiza la tercera ola democratizadora y sus afinidades casi indiscutidas con el modelo liberal estadounidense. Aunque también presta especial atención a las diferencias entre transiciones entendidas como proyecto político y como proyecto académico, para entender las salidas de diferente signo ideológico que se presentaron hacia fines del siglo XX.

En el sexto capítulo, el autor entra de lleno en el análisis del llamado "giro a la izquierda", entendido como un proceso sociopolítico donde un conjunto de gobiernos latinoamericanos alcanzara gran poder político, a partir de los debates que acarrea la denominación. Por su parte, y quizás en cierta confrontación con muchos análisis estrictamente económicos de izquierda, Lynch adopta la denominación entendiendo que estos gobiernos generaron una ruptura social, al comprometerse con la lucha por la democracia, la soberanía nacional y la integración social.

No obstante, también el autor se encarga de recuperar los debates en torno a la denominación en el campo académico como de la posibilidad de reagrupar dichos gobiernos en torno a más 
de una tendencia. Asimismo, Lynch analiza de cerca y como parte de las bases de giro a la izquierda, la oposición en torno al clivaje neoliberalismo-antineoliberalismo, en cierta medida análogo en muchos países donde se desarrollaron movimientos contra los ajustes económicos de corte ortodoxo. Y, por último, debe destacarse el recorrido realizado en torno a las ideologías de izquierdas y las nacionales-populares, sus filiaciones y desencuentros en la historia reciente.

El séptimo y último capítulo aborda una cuestión trascendental para Latinoamérica en nuestros días: la crisis del giro a la izquierda y la contraofensiva de la derecha. El autor asume que se trata de una crisis regional de mayor envergadura que la de un conjunto de gobiernos que, asociadas a los altos precios de las materias primas, viven una reversión a partir de su hegemonía política y la endeblez de las reformas emprendidas. Desde este punto de vista, Lynch discute la neutralización de la democracia en torno al binomio democracia liberal-autoritarismo populista, que pretenden algunos análisis rescatando, por el contrario, las particularidades del subcontinente. Lynch destaca el peso de las estructuras pasadas por el neoliberalismo como de las herramientas retomadas, en gran medida también influidas por el pasado, por los gobiernos nacional-populares de cara a la construcción de las democracias latinoamericanas en las primeras décadas del siglo XXI. Por consiguiente, el autor muestra cierta preocupación por la judicialización de la política como por los escándalos de corrupción ampliamente debatidos en la actualidad.
Por último, debe mencionarse el lugar que Lynch otorga a la contraofensiva derechista, entendida como regímenes contrarios a los nacional-populares de diverso origen: electoral, como germen de la misma fuerza política nacional-popular o mediante golpes de Estado, sean blandos o duros. En este sentido, el autor señala la vacancia de la hegemonía política en un contexto en el que en verdad los gobiernos nacional-populares vuelven electoralmente, aunque sin embargo se trata de un proceso abierto y actualmente jaqueado por las tremendas limitaciones económicas y políticas que impuso la pandemia por COVID-19.

El libro de Lynch aparece en un momento más que oportuno en el que los gobiernos latinoamericanos deberán enfrentar no solo la cuestión democrática sino la reconstrucción económica y social que las consecuencias del COVID-19 dejan en las sociedades. De esta forma, el aporte de Lynch en torno al significante democrático, su evolución a lo largo del tiempo y las precisiones latinoamericanas de las últimas experiencias políticas se torna esencial para repensar la construcción de los regímenes políticos en la actualidad y en el difícil futuro que nos avecina. Creemos que la salida que se presente a los actuales problemas de las sociedades latinoamericanas debe ser por la vía democrática, divorciada del neoliberalismo y con independencia económica y política para lograr construir un futuro mejor para todos. Dicho esto, el presente libro tiene mucho que aportar.

Ignacio Rossi Instituto del Desarrollo Humano Universidad Nacional General Sarmiento-Argentina 